\title{
Research on the Impact of the Price Adjustment of Refined Oil on Air Quality: Taking Hebei Province as an Example
}

\author{
Ting Zhao ${ }^{1}$ \\ ${ }^{1}$ School of Economics and Management, Nanjing University of Aeronautics and Astronautics, Nanjing, China \\ Correspondence: Ting Zhao, School of Economics and Management, Nanjing University of Aeronautics and \\ Astronautics, Nanjing, Jiangsu Province, China. Tel: 1-565-166-5912. E-mail: 2368565921@qq.com.
}

Received: April 30, 2018

Accepted: May 21, 2018

Online Published: June 5, 2018

doi:10.5539/ijef.v10n7p72

URL: https://doi.org/10.5539/ijef.v10n7p72

\begin{abstract}
With marketization of the refined oil price, the Chinese government still uses price adjustments of refined oil to control air pollution. In this paper, an event study analysis is used to investigate the impact of refined oil price adjustment on air quality of eleven cities in Hebei Province. It is found that the impact of increases in refined oil price is larger than the impact of decreases. This implies an improvement of air quality. And the higher the price increases, the larger the impact is on air quality. Hoverer, refined oil price adjustments are generally not too large, it suggests that suspension of price adjustment of refined oil is not a viable method to improve the air quality. Other policies such as raising vehicle emission standards and fuel quality may be considered.
\end{abstract}

Keywords: oil prices, air quality, rate of return, event study

\section{Introduction}

\subsection{The Current Situation of Refined Oil Price Adjustment Mechanism and Air Pollution in China}

At present, refined oil is priced by the government administrative pricing mechanism. The highest retail price of refined oil is based on the price of crude oil in the international market, the domestic cost of average processing and the appropriate profit is taken into consideration. On January 4, 2016, the "complete marketization" of refined oil prices was put on the agenda for the first time by the National Development and Reform Commission and was planned to be completed during the "13th Five-Year" period. On January 13, 2016, the National Development and Reform Commission decided to set the upper and lower limits for the domestic refined oil. The upper limit was set to 130 dollars per barrel and the lower limit was set to 40 dollars per barrel. Setting limits is to reduce the adverse impact of the excessively low oil price in the international market on the domestic oil product market and ensure the long-term safety of domestic energy. In particular, the lower limit is set to reduce the reverse impacts of low oil prices on energy conservation and emission reduction and air pollution control.

The development of China's characteristic economy has resulted in an increasing demand for energy and more serious environmental pollution and environmental pressure (Hill, 2013). In 2016, air quality of only 84 of the 338 cities in China reached the new air quality standard and $75.1 \%$ didn't reach the standard. The core areas of air pollution spread from Beijing, Tianjin and Hebei to the north of Henan and northwest of Shandong Province (Jiang et al., 2018). Especially in Hebei province, air quality of six cities ranked the last ten in both 2016 and 2017.

\subsection{The Relationship between Refined Oil Price Adjustment and Air Quality}

The State Development and Reform Commission said that using the price leverage of refined oil will help to control air pollution. For example, on December 5, 2015, the National Development and Reform Commission decided to postpone the adjustment of refined oil price in order to prevent the further deterioration of air quality. This idea of controlling air pollution with the price adjustment of refined oil has been fully reflected in our government's related measures. In the context of the "complete marketization" of refined oil prices which is planned to be completed during the "13th Five-Year" period, it is worth studying whether the price of refined oil has an impact on the air quality. Whether the measure of suspending adjusting the price of refined oil is feasible to control air quality. Whether the "complete marketization" of refined oil pricing will reduce China's air quality control measures and whether refined oil price fluctuations will lead to a severe air pollution situation in China. 
These problems deserve our attention.

\subsection{Literature Review}

At present, there are a lot of researches on price elasticity of refined oil. Many foreign scholars have found that gasoline demand is not sensitive to price (Brons et al., 2008; Arzaghi \& Squalli, 2015; Havranek \& Kokes, 2014). Lin and Prince (2013) find that the volatility of gasoline prices reduce demand for gasoline, but great volatility will reduce consumers' sensitivity to gasoline prices based on data of the USA. Lin and Zeng (2013) find that the price elasticity of gasoline in China is inelastic.

Reducing the use of motor vehicles by improving the fuel cost is a feasible way to reduce air pollution and promote energy conservation and emission reduction in China. However, the actual effect of the policy has not obtained a more consistent conclusion. Burk and Nishiitateno (2013) find that the increase in gasoline prices can promote consumers to use energy-efficient vehicles in the study of data from 132 countries in 132 countries from 1998 to 2010. Hirota and Pootyi (2006) and Li et al. (2012) find that the increase in gasoline prices will reduce the use of cars. Anderson and Sallee (2016) think that the fuel tax is the most effective and economical method to improve air pollution and the increase in fuel costs will help air pollution control. In the related research of China, results of Wei's (2009) study based on the CGE model obtained through numerical simulation also show that the fuel environment tax has an obvious effect on air pollution. Kang (2006) also believes that the price of refined oil will have an impact on the automotive industry and further have an impact on air quality through the motor vehicle transmission mechanism. On the contrary, Xi and Liang (2015) conduct an empirical study on the impact of oil price changes on air pollution through the motor vehicle transmission mechanism and results show that the increase in oil prices cannot change the air quality. Similarly, Barnett and Knibbs (2014) use a regression model to study the relationship between the refined oil prices and related pollutants, and the results show that changes in oil prices have no effect on air pollution.

There are few studies on the relationship between the price adjustment of refined oil and air quality at present. The main reasons are as follows: first, the increasingly severe problems of urban air quality have aroused the attention of the government and the academia in recent years; second is the availability of data and the inability to handle it. And the research results are different and even opposite which may be caused by different research samples and research methods.

\subsection{Hypotheses and Structure}

This paper assumes that refined oil price adjustments have an impact on air quality and price increasing adjustments will improve air quality and price decreasing adjustments will lead to the deterioration of air quality. Cities in Hebei province are chosen because we should know whether refines oil price adjustments have significant impacts on cities with poor air quality. This paper is divided into the following six parts: the first part is the introduction, the second part is the literature review, the third part will discuss the sample and method, the fourth part is the results and the last part is the summary.

\section{Method}

This paper uses event analysis methods to conduct research. The method of event analysis was first applied to the financial field, and it is an empirical research method to analyze the influence of a specific event on the value of the company. This method has the advantages of rigorous research theory, clear logic and simple calculation process. It has been applied to more and more fields to study the impact of specific events on organizational behaviors (Wang \& Zhu, 2012). The application of the event analysis method to energy products such as refined oil products is generally based on the study of the impact of refined oil price adjustments on energy stocks (Liu et al., 2013), or the study of the effects of extreme events on refined oil prices (Zhang et al., 2009). This paper creatively applies the event analysis method to the research on the relationship between refined oil price adjustment and air quality which can effectively avoid the interference of other factors.

\subsection{Data Frequency and Analysis Window}

The period chosen in this paper is from January 1st, 2015 to December 31st, 2017. During this period, China has already implemented the "Petroleum Prices Management Measures (Trial)" and domestic refined oil prices are adjusted every 10 working days based on international crude oil prices. During the three-year period, the National Development and Reform Commission has made a total of 50 adjustments to refined oil prices, of which 27 were raised and 23 were decreased. The event analysis method generally requires a longer window period and time saliency but China's refined oil price adjustments are frequent due to the implementation of the "Oil Prices Management Approach (Trial)". In order to meet the relevant requirements, this paper chooses events with larger price changes 25 days before which there is no price adjustment. This paper also combines the same 
incidents as an event in order to meet the relevant requirements. As shown in Table 1, this article finally selects a total of 10 refined oil price adjustment events including five price increasing events and five price decreasing events.

Table 1. Refined oil price adjustments during the three years

\begin{tabular}{cccccc}
\hline Date & Direction & Gasoline/Diesel (Yuan Per liter) & Date & Direction & Gasoline/Diesel (Yuan Per liter) \\
\hline $2015-01-12$ & $\downarrow$ & $0.18 / 0.23$ & $2016-08-04$ & $\downarrow$ & $0.22 / 0.215$ \\
$2015-01-26$ & $\downarrow$ & $0.27 / 0.30$ & $2016-08-18$ & $\uparrow$ & $0.13 / 0.14$ \\
$2015-02-09$ & $\uparrow$ & $0.21 / 0.24$ & $2016-09-01$ & $\uparrow$ & $0.205 / 0.2$ \\
$2015-02-27$ & $\uparrow \downarrow$ & $0.29 / 032$ & $2016-09-18$ & $\downarrow$ & $0.155 / 0.15$ \\
$2015-03-26$ & $\downarrow \downarrow$ & $2016-10-19$ & $\uparrow \checkmark$ & $0.355 / 0.34$ \\
$2015-04-10$ & $\uparrow$ & $0.18 / 0.20$ & $2016-11-16$ & $\downarrow$ & $0.365 / 0.355$ \\
$2015-04-24$ & $\uparrow$ & $0.09 / 0.10$ & $2016-11-30$ & $\uparrow$ & $0.175 / 0.17$ \\
$2015-05-11$ & $\uparrow$ & $0.22 / 0.24$ & $2016-12-14$ & $\uparrow \checkmark$ & $0.435 / 0.42$ \\
$2015-06-08$ & $\downarrow$ & $0.19 / 0.21$ & $2017-01-12$ & $\uparrow$ & $0.07 / 0.07$ \\
$2015-07-07$ & $\downarrow$ & $0.08 / 0.09$ & $2017-01-25$ & $\downarrow$ & $0.07 / 0.07$ \\
$2015-07-21$ & $\downarrow$ & $0.07 / 0.08$ & $2017-02-14$ & $\uparrow$ & $0.05 / 0.05$ \\
$2015-08-04$ & $\downarrow$ & $0.20 / 0.23$ & $2017-03-14$ & $\downarrow$ & $0.085 / 0.085$ \\
$2015-08-18$ & $\downarrow$ & $0.16 / 0.18$ & $2017-03-28$ & $\downarrow \checkmark$ & $0.23 / 0.22$ \\
$2015-09-01$ & $\downarrow$ & $0.16 / 0.18$ & $2017-04-12$ & $\uparrow$ & $0.2 / 0.19$ \\
$2015-09-16$ & $\uparrow$ & $0.09 / 0.10$ & $2017-05-11$ & $\downarrow$ & $0.25 / 0.235$ \\
$2015-10-20$ & $\uparrow$ & $0.07 / 0.08$ & $2017-05-25$ & $\uparrow$ & $0.14 / 0.135$ \\
$2015-11-03$ & $\downarrow$ & $0.04 / 0.04$ & $2017-06-09$ & $\downarrow$ & $0.18 / 0.175$ \\
$2015-11-17$ & $\downarrow$ & $0.09 / 0.11$ & $2017-06-23$ & $\downarrow$ & $0.025 / 0.024$ \\
$2015-12-01$ & $\downarrow \downarrow$ & $2017-07-21$ & $\uparrow$ & $0.075 / 0.075$ \\
$2016-01-13$ & $\downarrow$ & $0.06 / 0.07$ & $2017-08-04$ & $\uparrow$ & $0.175 / 0.165$ \\
$2016-04-26$ & $\uparrow \downarrow$ & $2017-09-15$ & $\uparrow$ & $0.095 / 0.095$ \\
$2016-05-11$ & $\uparrow$ & $0.11 / 0.12$ & $2017-09-29$ & $\uparrow \checkmark$ & $0.21 / 0.195$ \\
$2016-05-25$ & $\uparrow$ & $0.14 / 0.135$ & $2017-11-02$ & $\uparrow$ & $0.15 / 0.15$ \\
$2016-06-8$ & $\uparrow$ & $0.165 / 0.16$ & $2017-12-28$ & $\uparrow$ & $0.265 / 0.25$ \\
$2016-07-21$ & $\downarrow$ & $0.12 / 0.115$ & & & $0.07 / 0.07$ \\
\hline
\end{tabular}

Source: China financial information network.

This paper selects 11 prefecture-level cities in Hebei Province as the research object. The 11 cities are Hengshui, Shijiazhuang, Baoding, Xingtai, Handan, Tangshan, Qinhuangdao, Zhangjiakou, Chengde, Langfang and Luzhou. Data of the 11 cities' AQI index are collected from the Chinese Ministry of Environmental Protection to study effects of the refined oil price adjustments on air quality. AQI is classified into six levels $(0 \sim 50,51 \sim 100$, 101 150, 151 200, 201 300 and >300). When it is smaller than 50, air quality is satisfactory without risk. The higher the AQI value, the greater the level of air pollution and the greater the health concern. For example, an AQI value of 50 represents good air quality with little potential to affect public health. An AQI value over 300 represents hazardous air quality. AQI covers more pollutants than the previous Air Pollution Index (API) and could help inform health-related decisions.

The event analysis method first needs to select the estimation window and the event window. This paper takes 10 days after the announcement of the price adjustment as the event window and 25 days before as the estimation window to estimate the normal returns.

\subsection{AQI Returns}

The event analysis method requires the normal rate of return of the study object be calculated when the event does not occur, and then the abnormal rate of return of the object after the event is calculated based on the normal rate of return. In this paper, AQI refers to the rate of return of air quality.

This paper takes the constant average model to calculate the normal rate of return of air quality. Since air quality does not depend on any economic model, it is impossible to choose an economic model but only a statistical model based on statistical assumptions of the behavior of asset return to calculate the normal rate of returns.

The constant average model is to estimate the average rate of return of the urban air quality during the estimation period as the normal rate of return within the event window. 


$$
\bar{R}_{i}=\sum_{t=-25}^{-1} r_{i t} / 25
$$

Where $r_{i t}$ is the AQI is the return on AQI of city $i$ on day $\mathrm{t}, \bar{R}_{i}$ is the average return on asset $i$.

\subsection{Model Estimation and Hypothesis Testing}

Assuming $\mathrm{t}=0$ is the event date, the model for normal performance is estimated over the estimation period ( -25 , $-1)$ and abnormal returns are calculated over the event period $(1,12)$. We standardize abnormal returns and calculate the overall changes on standardized abnormal returns of cities during the event period as specified in equation (3). This ensures that the analysis is identically distributed.

$$
\begin{aligned}
& S A R_{i t}=\frac{A R_{i t}}{\sqrt{S_{A R_{i t}{ }^{2}}}} \\
& S_{A R_{i t}}{ }^{2}=\frac{\sum_{t=t l}^{t 2}\left(A R_{i t} \overline{A R}_{i t}\right)^{2}}{t 2-t 1}, t 1, t 2 \in[1,10] \\
& T S A R_{i}=\sum_{t=t l}^{t 2} S A R_{i t}, t_{1}, t_{2} \in[1,12] \\
& \text { CTSAR }=\sum_{i=1}^{N} T_{S A R}
\end{aligned}
$$

Where $S_{A R_{i t}}$ is the standardized abnormal returns on day $t$ of cityi, $S_{A R_{i t}}{ }^{2}$ is the variance of abnormal returns of city i over the event period. $T S A R_{i}$ is the overall changes on standardized abnormal returns of city $i$. According to the statistical principles, when $\mathrm{N}<30$ and the population standard deviation is unknown the $\mathrm{t}$ - test is as follows:

$$
t_{i}=\frac{T S A R_{i}}{\sqrt{t 2-t l+1}}
$$

Where $t_{i}$ obeys the distribution T (n-1).

\section{Results}

Different from existing studies adopting a mechanism or other indirect methods, this paper takes an event study analysis to study the direct relationship between refined oil price increasing events and decreasing events and air quality. Results of price decreasing events are as shown in Table 2. Refined oil price decreasing events have insignificant effects on air quality of eleven cities in Hebei Province. The results of price increasing events are as shown in Table 4 which are more significant. Responses to the price increasing event with the adjustment of 0.165 per liter and 0.16 per liter for gasoline and diesel on April 26,2016 are insignificant. However, the responses to the price increasing events on October 19, 2016 and December 14,2016 are very significant with a larger rate of price increase. Gasoline and diesel are increased by 0.355 per litre and 0.34 per litre on October 19 , 2016 and 0.435 per litre and 0.42 per litre on December 14, 2016.

Table 2. Results of refined oil price decreasing events

\begin{tabular}{ccccccccccccc}
\hline & Hengshui & Shijiazhuang & Baoding & Xingtai & Handan & Tangshan & Qinhuangdao & Zhangjiakou & Chengde & Langfang & Cangzhou \\
\hline $2015 / 3 / 26$ & 0.52 & 0.48 & 0.10 & $0.07^{*}$ & 0.49 & 0.37 & 0.49 & $0.05^{*}$ & 0.32 & 0.85 & 0.30 \\
$2015 / 7 / 21$ & 0.54 & $0.02^{* *}$ & $0.07^{*}$ & 0.28 & 0.82 & 0.14 & $0.03^{* *}$ & $0.01^{* * *}$ & 0.42 & 0.59 & $0.03^{* *}$ \\
$2015 / 12 / 1$ & $0.09 *$ & 0.20 & $0.02^{* *}$ & 0.16 & $0.02^{* *}$ & 0.68 & $0.09^{*}$ & 0.91 & 0.21 & 0.85 & 0.32 \\
$2016 / 7 / 21$ & 0.28 & 0.67 & 0.16 & $0.07^{*}$ & 0.52 & $0.00^{* * *}$ & 0.37 & 0.51 & $0.05^{*}$ & 0.54 & 0.25 \\
$2017 / 3 / 28$ & 0.37 & 0.23 & 0.24 & 0.12 & $0.01^{* * *}$ & 0.18 & 0.40 & 0.42 & 0.18 & 0.48 & 0.16 \\
\hline
\end{tabular}

Note. *,**,***mean significant at the10\%-level, 5\%-level and 1\%-level.

Table 3. Results of refined oil price increasing events

\begin{tabular}{cccccccccccc}
\hline & Hengshui & Shijiazhuang & Baoding & Xingtai & Handan & Tangshan & Qinhuangdao ZHangjiakou Chengde Langfang Cangzhou \\
\hline $2015 / 2 / 27$ & $0.00^{* * *}$ & 0.27 & 0.10 & $0.00^{* * *}$ & $0.00^{* * *}$ & 0.27 & 0.50 & 0.17 & 0.54 & 0.49 & $0.02^{* *}$ \\
$2016 / 4 / 26$ & 0.90 & 0.22 & 0.26 & 0.45 & $0.08^{*}$ & 0.44 & 0.93 & 0.72 & $0.02^{* *}$ & $0.08^{*}$ & 0.81 \\
$2016 / 10 / 19$ & $0.00^{* * *}$ & $0.00^{* * *}$ & $0.00^{* * *}$ & $0.01^{* * *}$ & $0.03^{* *}$ & $0.05^{* *}$ & $0.03^{* *}$ & $0.05^{* *}$ & $0.00^{* * *}$ & 0.34 & $0.00^{* * *}$ \\
$2016 / 12 / 14$ & $0.03^{* *}$ & $0.03^{* *}$ & $0.04 * *$ & $0.01 * * *$ & $0.01^{* * *}$ & $0.06^{*}$ & $0.09^{*}$ & 0.69 & 0.13 & $0.07^{*}$ & 0.12 \\
$2017 / 9 / 29$ & $0.00^{* * *}$ & $0.00^{* * *}$ & $0.01^{* * *}$ & $0.00^{* * *}$ & $0.00^{* * *}$ & 0.39 & $0.07 *$ & 0.88 & 0.47 & $0.05^{* *}$ & $0.01^{* * *}$ \\
\hline
\end{tabular}


The results of the whole abnormal rate of air quality returns in Hebei are shown in Table 4 . The directions of the impact of price decreasing events on air quality in Hebei province are two negative, two positive and one insignificant, while the directions of the impact of price increasing events on air quality in Hebei province is four negative and one insignificant.

Table 4. Results of CTSAR

\begin{tabular}{cccc}
\hline Price decreasing events & CTSAR & Price increasing events & CTSAR \\
\hline $2015 / 3 / 26$ & 4.09 & $2015 / 2 / 27$ & -72.61 \\
$2015 / 7 / 21$ & -24.46 & $2016 / 4 / 26$ & 2.22 \\
$2015 / 12 / 1$ & 50.12 & $2016 / 10 / 19$ & -140.32 \\
$2016 / 7 / 21$ & -10.13 & $2016 / 12 / 14$ & -78.29 \\
$2017 / 3 / 28$ & 24.21 & $2017 / 9 / 29$ & -56.26 \\
\hline
\end{tabular}

\section{Discussions}

This paper takes the event analysis method and take eleven cities in Hebei Province as the research objects to discusses the impacts of refined oil price adjustments on air quality. The following conclusions are obtained:

First of all, refined oil price increasing and decreasing adjustments have a different impact on air quality. In general, the impacts of the price decreasing events on air quality of the eleven cities in Hebei Province are insignificant, and the impacts of the price increasing events on urban air quality are relatively significant. This may be due to the fact that private cars in major cities in China are gradually approaching saturation. Once the oil price is decreased, people cannot predict that the adjustment, so it will not attract new buyers to purchase private cars. The existing private car owners as well will not purchase more refined oil. Therefore, the refined oil price decreasing events have an insignificant impact on the air quality.

Secondly, the impacts of the refined oil price increasing events on air quality are related to the range of the price adjustment. The greater in refined oil prices increase, the greater the impacts on air quality are. This is due to the increase in China's per capita income and the lack of sensitivity of the high-income population to price changes. A smaller price adjustment will not affect people's use of the car, while a substantial increase in oil prices will increase the use of non-private vehicles such as taxis. Negative effects are caused and the air quality is relatively better.

Finally, the impacts of the price decreasing events on the air quality are not obvious and the impacts of the price increasing events on the AQI index is significantly negative. That is, the increase in refined oil prices will improve urban air quality.

From the empirical findings of this paper, the large increases in refined oil prices will lead to better air quality. However, there has been few large price adjustments from 2015 to 2017. Therefore, suspending refined oil price adjustments or raising the refined oil prices by a small margin will not improve urban air quality. On the contrary, the government's excessive intervention in refined oil prices will not benefit for the healthy development of the refined oil market. This requires advancement of other measures: the mandatory promotion of vehicle emission standards and oil quality, the promotion of research and production of new energy vehicles, and the construction of public transport systems.

There are some contributions in this paper. Firstly, this paper applies a new method to study the relationship between air quality and refined oil prices which can give some enlightenment for following studies. Secondly, our results can give some suggestions for the government that oil price adjustment is not an appropriate measure to improve air quality and marketization of the refined oil price won't affect air quality in the long term.

However, my study has some limitations such as the sample is not very sufficient and this paper ignores the continuous price decreasing and increasing events. In the future, I may do research on relationship between refined oil price adjustments and air quality of all main cities in China and take continuous price decreasing and increasing events into consideration which may make results more convincing.

\section{Acknowledgments}

I'm grateful to professor Zha who gives me some inspiration about my topic.

\section{References}

Anderson, S. T., \& Sallee, J. M. (2016). Designing Policies to Make Cars Greener. Annual Review of Resource Economics, 8, 113-124. https://doi.org/10.1146/annurev-resource-100815-095220 
Arzaghi, M., \& Squalli, J. (2015). How price inelastic is demand for gasoline in fuel-subsidizing Economies? Energy Economics, 50, 117-124. https://doi.org/10.1016/j.eneco.2015.04.009

Barnett, A. G., \& Knibbs, L. D. (2014). Higher fuel prices are associated with lower air pollution levels. Environment International, 66, 88-91. https://doi.org/10.1016/j.envint.2014.01.029

Brons, M., Nijkamp, P., Pels, E., \& Rietveld, P. (2008). A Meta-analysis of the Price Elasticity of Gasoline Demand. A SUR Approach. Energy Economics, 30, 2105-2122. https://doi.org/10.1016/j.eneco.2007.08.004

Burke, P. J., \& Nishitateno, S. (2013). Gasoline prices, gasoline consumption, and new-vehicle fuel economy: Evidence for a large sample of countries. Energy Economics, 36, 363-370. https://doi.org/10.1016/j.eneco.2012.09.008

Havranek, T., \& Kokes, O. (2014). Income Elasticity of Gasoline Demand: A Meta-Analysis. Energy Economics, 47, 77-86. https://doi.org/10.1016/j.eneco.2014.11.004

Hill, S. (2013). Reforms for a Cleaner, Healthier Environment in China. Oecd Economics Department Working Papers. https://doi.org/10.1787/5k480c2dh6kf-en

Hirota, K., \& Poot, J. (2006). An International Survey and Statistical Analysis of the Effect of Taxes on Car Use and $\mathrm{CO}_{2}$ Emission. Studies in Regional Science, 35, 1109-1120. https://doi.org/10.2457/srs.35.1109

Jiang, L., Zhou, H. F., Bo, L., \& Chen, Z. S. (2018). Analysis of Socio-Economic Factors of Air Quality Index (AQI)-Based on Exponential Decay Effect Perspective. Journal of Environmental Science, 38, 390-398. https://doi.org/10.13671/j.hjkxxb.2017.0181

Kang, L., Zhang, Y. G., \& Hui, X. G. (2006). The Influence of China's Refined Oil Price Adjustment on Related Industries under the Current Pricing Mechanism. Special Zone Economy, 12, 119-121.

Li, S., Linn, J., \& Muehlegger, E. (2012). Gasoline Taxes and Consumer Behavior. Social Science Electronic Publishing, 6, 302-342. https://doi.org/10.2139/ssrn.2010202

Lin, C. Y. C., \& Prince, L. (2013). Gasoline price volatility and the elasticity of demand for gasoline. Energy Economics, 38, 111-117. https://doi.org/10.1016/j.eneco.2013.03.001

Lin, C. Y. C., \& Zeng, J. (2013). The elasticity of demand for gasoline in China. Energy Policy, 59, 189-197. https://doi.org/10.1016/j.enpol.2013.03.020

Liu, M., Yang, Y. Z., \& Sun, W. X. (2013). The Impact of the Price Adjustment of Refined Oil on the Yield of Energy Stocks-Based on the Method of Event Analysis. Economic Review, 109-117. https://doi.org/10.19361/j.er.2013.03.011

Wang. L., \& Zhu, Z. (2012). H. Research and Innovation of Event Analysis Method and Its Application Progress. Social Sciences Abroad, 138-144.

Wei, W. X. (2009). Analysis of China's Energy Environment Policy Based on CGE Model. Statistical research, 26, 3-12. https://doi.org/10.3969/j.issn.1002-4565.2009.07.001

Xi, P. H., \& Liang, R. B. (2015). Impact of Oil Price Changes on Air Pollution: Using Motor Vehicles as a $\begin{array}{lllll}\text { Transmission Approach. } & \text { China Industrial }\end{array}$ https://doi.org/10.19581/j.cnki.ciejournal.2015.10.008

Zhang, X., Yu, L., Wang, S., \& Lai, K. K. (2009). Estimating the impact of extreme events on crude oil price: An EMD-based event analysis method. Energy Economics, 31, 768-778. https://doi.org/10.1016/j.eneco.2009.04.003

\section{Copyrights}

Copyright for this article is retained by the author(s), with first publication rights granted to the journal.

This is an open-access article distributed under the terms and conditions of the Creative Commons Attribution license (http://creativecommons.org/licenses/by/4.0/). 